J Chron Dis 1972, Vol. 25, pp. 567-580. Pergamon Press. Printed in Great Britain

\title{
CORONARY DISEASE IN STAVELEY, DERBYSHIRE WITH AN INTERNATIONAL COMPARISON WITH THREE TOWNS IN MARION COUNTY, WEST VIRGINIA
}

\author{
I. T. T. Higgins, M. D. Lockshin, ${ }^{*}$ J. C. Gilson, A. L. Cochrane, \\ H. Campbell, W. E. Waters, B. G. Ferris, Jr., M. Oh and M. W. Higgins \\ Department of Epidemiology, School of Public Health, \\ University of Michigan, Ann Arbor, Mich., U.S.A. \\ and \\ The Medical Research Council's Pneumoconiosis and Epidemiological Research Units, \\ Cardiff, Glamorgan, England \\ and \\ Department of Physiology, School of Public Health, \\ Harvard University, Buston, Mass., U.S.A.
}

(Received 22 February 1971; in final form 11 August 1971)

\section{INTRODUCTION}

THE REPORTED death rate from coronary heart disease in men aged 35-64 is approximately half as high again in the United States as in the United Kingdom. Reid and his colleagues [1] have shown that the prevalence of cardiac pain and the frequency of electrocardiographic changes suggestive of myocardial ischaemia are commoner in middle-aged American than in British males. Their observations were made on occupational groups which may be selected to favor the inclusion of fitter men. International comparisons which are based on defined communities and which include both men who are working and men who have retired are needed. During the course of a study of respiratory disease in a representative sample of the English industrial town of Staveley, Derbyshire [2], observations on coronary disease were therefore included. The aim was to compare the findings there with those of a study which had been carried out in mining communities in Marion County, West Virginia [3]. In addition to the international comparison, we also wished to see if the prevalence of coronary disease differed among miners, foundry workers, and men who were not exposed occupationally to dust.

\footnotetext{
*Formerly Epidemic Intelligence Service Officer, United States Public Health Service, Communicable Disease Center, Epidemiology Program, Atlanta, Georgia

This work was supported by Grant No. OH 00243-01 from the American Medical Association's Research Foundation Committee for Research on Tobacco and Health.
} 


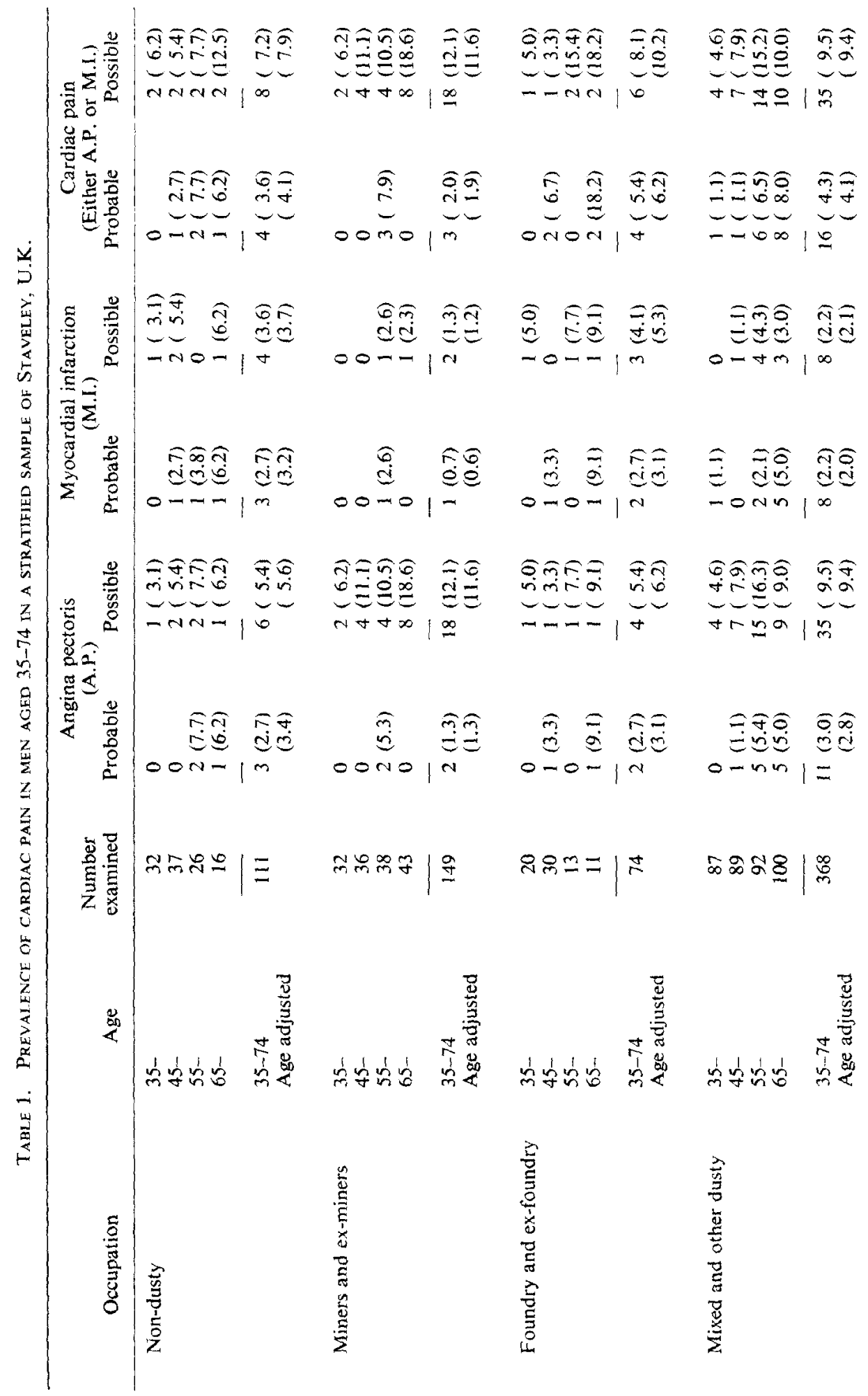




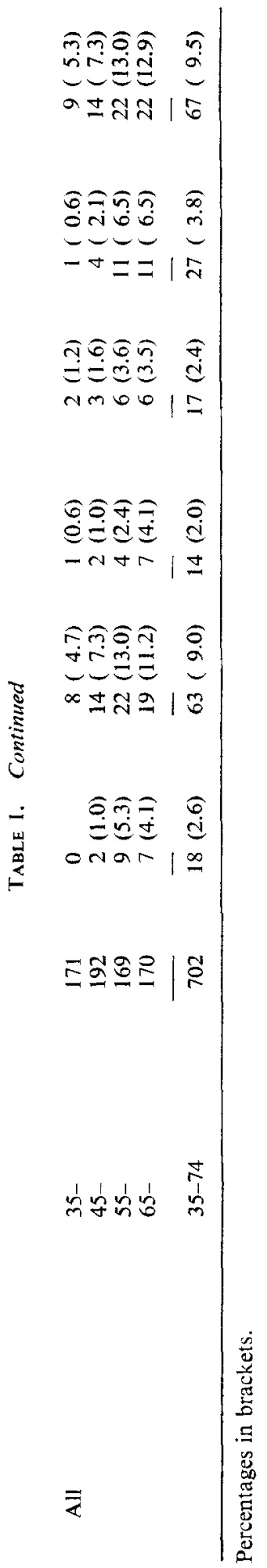




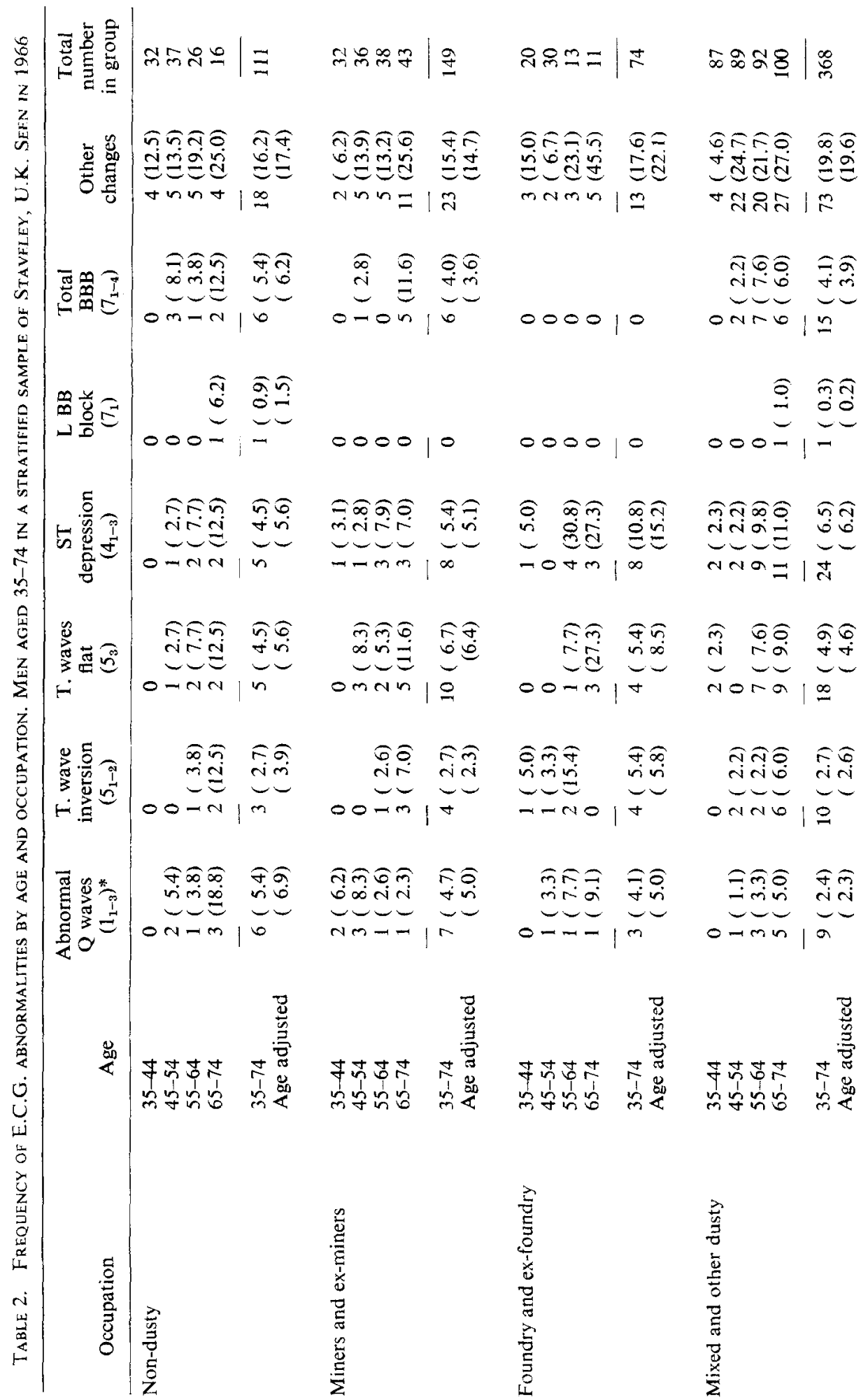




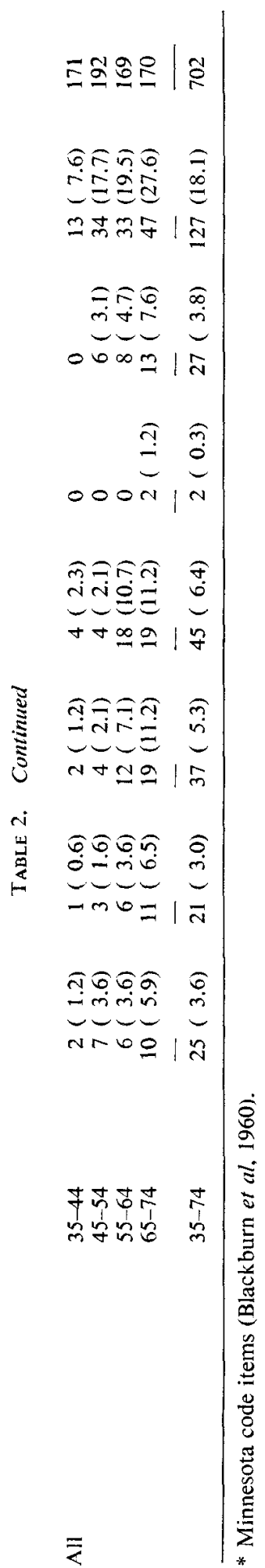




\section{PROCEDURE AND METHODS}

Staveley is a town of some 18,000 inhabitants. The predominant occupations are mining, foundry, chemical, railway work and retail trade. A census was carried out by Marketing Research Interviewing (now Ellis Marketing Research) during May 1966. On the basis of information obtained at the census a representative sample of men aged 35 to 74 who lived in the town, was selected. The sample was stratified by age and occupation. Four occupational groups were used: miners and exminers, foundry and exfoundry workers, other and mixed dust exposed and nondust exposed workers. The members of the sample were seen at a center during June and July 1966. Each man was allocated at random to one of four physicians for interview. Standardized questions were asked about chest pain and other respiratory symptoms and the occurrence of heart attacks. A questionnaire broadly similar to that advocated by Rose [4] and the British Medical Research Council [5] to identify persons with cardiac pain and respiratory symptoms respectively was used. Smoking habits and occupational details were also included. A twelve-lead, resting electrocardiogram was taken. All the electrocardiograms were coded by one observer (ITTH) according to the Minnesota Code [6]. The blood pressure was measured using a standard sphygmomanometer. All the blood pressure measurements were taken by one of us (M.D.L.) to minimize observer variation. Height and weight were measured with the subject lightly clad and without shoes. The three-quarter second and one second forced expiratory volumes (F.E.V ${ }_{\cdot 1 \cdot 0}$ and F.E.V $\cdot_{0 \cdot 75}$ respectively) and the forced vital capacity (F.V.C.) were measured [7]. A water filled, direct reading Poulton Spirometer [8] was used. The mean of three readings after a practice blow was corrected to B.T.P.S.

\section{Cardiac pain}

Subjects were classified on the basis of their answers to the chest pain questions as having probable or possible angina pectoris and probable or possible myocardial infarction. The criteria were as follows: Probable angina: retrosternal or left chest and arm pain or discomfort brought on by exertion and necessitating rest or reduction in speed or nitroglycerine and relieved by rest or nitroglycerine within $15 \mathrm{~min}$; Possible angina: any chest pain or discomfort or any arm, neck, or jaw pain brought on by exertion and relieved by rest which failed to meet the requirements for probable angina; Probable myocardial infarction: a heart attack previously diagnosed and treated with bed rest or anticoagulants; Possible myocardial infarction: history of a heart attack not treated as above or a history of severe or moderate retrosternal or left chest and left arm pain lasting for $30 \mathrm{~min}$ to $24 \mathrm{hr}$ and not known to be due to another cause. The term cardiac pain has been used to indicate those who had either or both types of pain.

\section{Coronary disease}

Any man with probable cardiac pain was considered to have coronary disease. In addition coronary disease was diagnosed on the basis of E.C.G. abnormalities. The E.C.G. abnormalities were classified probable and possible coronary disease as follows: Probable: abnormal Q waves, T wave inversion, ST depression or complete left bundle-branch block; Possible: flat $T$ waves and other categories of bundlebranch block. Only those with probable categories were considered to have coronary disease. 


\section{Response rates}

In Marion County, West Virginia, 83 per cent of the men aged 20-69 yr were seen. In the present survey over 92 per cent of the sample of men aged 35-74 were seen.

In order to compare the present survey with that carried out in West Virginia, the results in West Virginia have been reanalyzed for decennial groups aged 35-64 yr.

\section{RESULTS}

\section{Cardiac pain}

Table 1 shows the prevalence of the four categories of cardiac pain in the men aged 35-74 in Staveley. The age-adjusted prevalences are calculated assuming that each occupational group was distributed as in the whole sample. There are no striking differences between the occupational categories.

Miners and exminers recorded a lower prevalence of myocardial infarction-type pain and also of probable angina than the other groups. But possible angina was commoner among them. The reason for this inconsistency is not clear. It may possibly have been due to the difficulty of differentiating chest discomfort or pain due to shortness of breath from angina. The numbers are small and the differences shown do not reach conventional levels of statistical significance. There are no other suggestive occupational differences.

\section{E.C.G. abnormalities}

Table 2 shows the frequency of E.C.G. changes relevant to coronary disease. The categories are those of the Minnesota Code [6]. 'Other changes' included high $\mathrm{T}$ waves, axis deviation, right bundle-branch block, arrhythmias, etc. It is important to realize when considering this table that there can be overlap between the various categories. There are no striking differences between the occupational groups. Foundrymen had a higher prevalence of ST depression than other workers. But the numbers are small and the difference is not statistically significant $(p>0.1)$. Nondusty workers recorded slightly more abnormal $\mathrm{Q}$ waves than others. Miners and exminers and the mixed and other group, which included men who had worked in mining as well as in other dusty jobs, had a lower frequency of $\mathrm{T}$ wave inversion. But none of these differences approach statistical significance.

Table 3 shows the relationship between angina pectoris and myocardial infaretion in the whole sample. Eighteen men had probable angina, 14 had probable myocardial infarction and five of them had both types of pain. Altogether, therefore, there were 27 men, who were considered to have probable coronary disease on the basis of their answers to the questionnaire.

TABLE 3. RELATIONSHIP BETWEEN ANGINA PECTORIS AND MYOCARDIAL INFARCTION. MEN AGED $35-74$. Seen in 1966. Stratified sample of Stavelfy, U.K.

\begin{tabular}{ccccc}
\hline Myocardial infarction & Probable & $\begin{array}{c}\text { Angina pectoris } \\
\text { Possible }\end{array}$ & Absent & Total \\
\hline Probable & 5 & 3 & 6 & 14 \\
Possible & 1 & 9 & 7 & 17 \\
Absent & 12 & 51 & 608 & 671 \\
Total & 18 & 63 & 621 & 702 \\
\hline
\end{tabular}


Table 4 shows the relationship between the categories of pain and E.C.G. abnormalities. It explores in detail the nine cells from Table 3 and relates them to E.C.G. changes. Unlike Table 2 there is no overlap between the E.C.G. categories in this table. Overlap was eliminated by considering the E.C.G. categories in sequence. All tracings which showed $Q$ wave abnormalities irrespective of whether they also showed other abnormalities were extracted first; tracings showing $\mathrm{T}$ wave inversion without abnormal Q waves were extracted next, then tracings with ST depression, left complete bundle-branch block and the other abnormalities. All possible permutations of angina and myocardial infarction have been shown.

TABLE 4. E.C.G. Findings IN THOSE WITH AND WITHOUt CARdiaC PAIN. MeN AGEd 35-74 IN A STRATIFIEd SAMPle of Staveley, U.K.

\begin{tabular}{|c|c|c|c|c|c|c|c|c|c|c|c|c|}
\hline \multirow[b]{2}{*}{$\begin{array}{l}\text { E.C.G. } \\
\text { changes }\end{array}$} & \multirow[b]{2}{*}{$\begin{array}{l}\text { Minnesota } \\
\text { code }\end{array}$} & \multicolumn{6}{|c|}{ Probable } & \multicolumn{3}{|c|}{ Possible } & \multirow{2}{*}{ 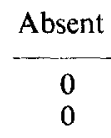 } & \multirow[b]{2}{*}{$\begin{array}{c}\text { Total } \\
\text { examined }\end{array}$} \\
\hline & & $\begin{array}{l}\text { M.I.* } \\
\text { A.P. }\end{array}$ & $\begin{array}{l}+ \\
+\end{array}$ & + & $\begin{array}{r}+ \\
0\end{array}$ & $\begin{array}{l}? \\
+\end{array}$ & $\begin{array}{l}0 \\
+\end{array}$ & $?$ & $\begin{array}{l}? \\
0\end{array}$ & $\begin{array}{l}0 \\
?\end{array}$ & & \\
\hline Abnormal $Q$ waves & $1_{1-3}$ & & 1 & 1 & 1 & 0 & 2 & 1 & 0 & 2 & 17 & 25 \\
\hline $\mathrm{T}$ wave inversion & $5_{1-2}$ & & 1 & 0 & 1 & 0 & 0 & 0 & 0 & 1 & 13 & 16 \\
\hline ST depression & $4_{1-3}$ & & 1 & 0 & 0 & 0 & 0 & 2 & 0 & 1 & 29 & 33 \\
\hline L BBB & $7_{1}$ & & 0 & 0 & 0 & 0 & 0 & 0 & 0 & 0 & 2 & 2 \\
\hline Flat $T$ waves & $5_{3}$ & & 1 & 1 & 0 & 0 & 1 & 1 & 1 & 2 & 16 & 23 \\
\hline BRB & 72 & & 0 & 0 & 0 & 0 & 0 & 0 & 0 & 5 & 15 & 20 \\
\hline Other & $2,3,6$ & & & & & & & & & & & \\
\hline (exclude $8_{7-8}$ ) & 8 or 9 & & 0 & 0 & 1 & 0 & 1 & 3 & 0 & 9 & 66 & 80 \\
\hline None & $1_{0}$ & & 1 & 1 & 3 & 1 & 8 & 2 & 6 & 31 & 450 & 503 \\
\hline Total & & & 5 & 3 & 6 & 1 & 12 & 9 & 7 & 51 & 608 & 702 \\
\hline
\end{tabular}

*M.I.: Myocardial Infarction by Questionnaire.

A.P.: Angina Pectoris by Questionnaire.

Table 5 shows that in addition to the 27 men already considered to have probable coronary disease on the basis of the questionnaire, there were 76 , who had probable coronary disease on the basis of E.C.G. changes, eight of them being common to both groups. In all, therefore, there were 95 men who had probable coronary disease by either pain or E.C.G. criteria.

It is clear from Table 5 that in identifying persons with coronary disease emphasis has been put on E.C.G. criteria. The correlation between cardiac pain and E.C.G. changes believed to indicate coronary disease is not particularly high. Thus, over half of those diagnosed as having coronary disease on the basis of probable cardiac pain had no E.C.G. abnormalities. And 80 per cent of those with probable E.C.G. abnormalities had no pain.

Table 5. Relationship between Cardiac pain and E.C.G. Changes suggestive of Coronary disease. Men aged 35-74 in a STRATified sample of Staveley, U.K., in 1966

\begin{tabular}{ccccc}
\hline E.C.G. changes & Probable & $\begin{array}{c}\text { Cardiac pain } \\
\text { Possible }\end{array}$ & Absent & Total \\
\hline Probable & 8 & 7 & 61 & 76 \\
Possible & 5 & 21 & 97 & 123 \\
Absent & 14 & 39 & 450 & 503 \\
Total & 27 & 67 & 608 & 702 \\
\hline
\end{tabular}


Coronary Disease in Staveley, Derbyshire

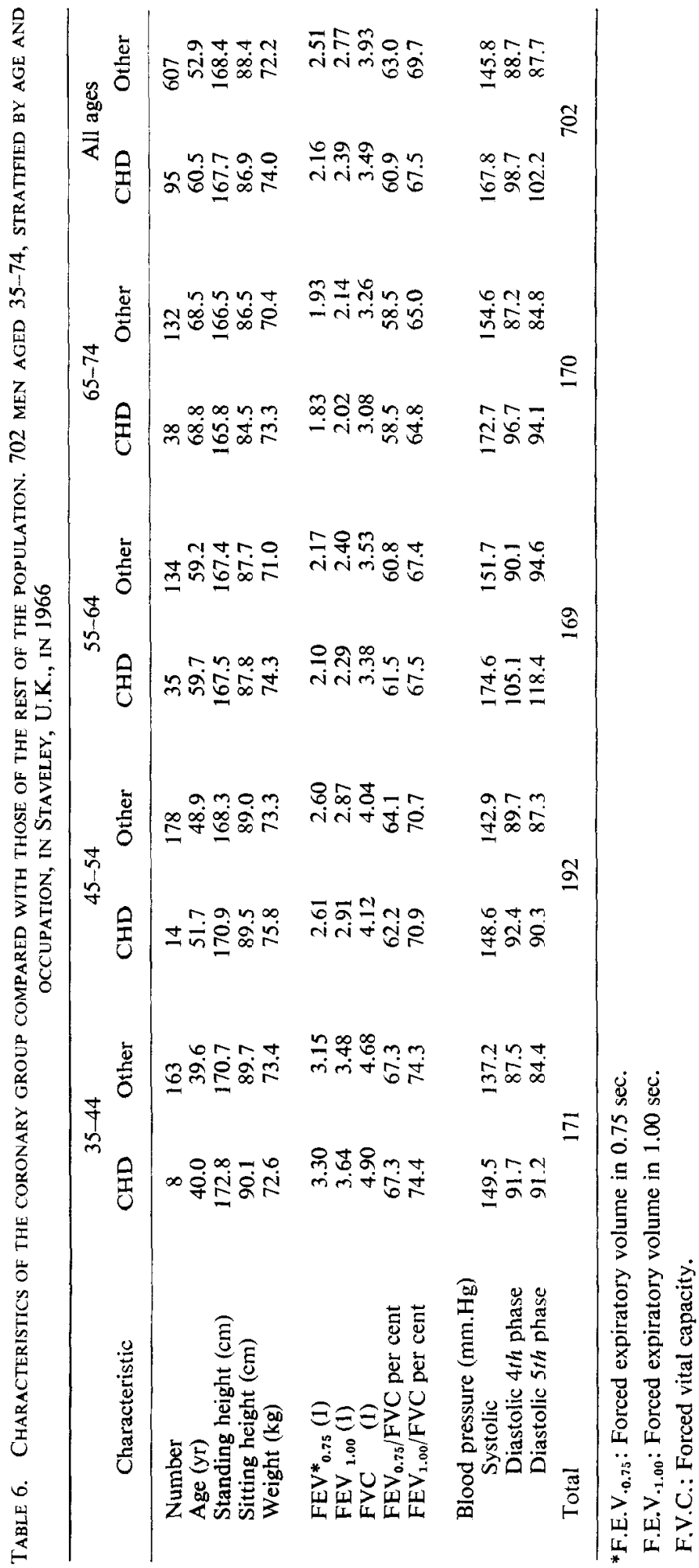


Comparison of coronary and other groups

Table 6 compares these 95 men with the others in relation to the relevant characteristics which were measured. The coronary group was $7.6 \mathrm{yr}$ older than the others. Caution is therefore needed in interpreting any differences between the two groups in the 'all ages' column. 'I he coronaries were heavier than the others. This was consistent in each decennial age group over $45 \mathrm{yr}$. It is possible that the true difference in weight between the groups may be somewhat understated since some of the coronary group may have been advised to lose weight. In the 55-64 and 65-74 age groups the F.E.V. and the F.V.C. were slightly lower among the coronaries than among the noncoronaries. In the 45-54 age group there was little difference in lung function between them; but in the $35-44$ age group the lung function values were higher in the coronary group. In each decennial group the blood pressure, both systolic and diastolic, was consistently higher in the coronary than in the other group.

Table 7 compares smoking habits in the coronary and other groups. A lower proportion of the coronaries had never smoked. A higher proportion of them had given up smoking. Presumably because of the higher proportion of exsmokers among them, a smaller proportion of coronaries than of the others were currently smoking cigareltes.

TABLE 7. COMPaRISON OF SMOKING HaBits OF MEN WITH AND WITHOUT CORONARY DISEASE. Men STRATIFIED by aGe and oCCUPATION SEEN AT STAVELEy, U.K., IN 1966

\begin{tabular}{|c|c|c|c|c|c|}
\hline \multicolumn{6}{|c|}{ Men with coronary disease } \\
\hline Age & Non-smokers & Ex-smokers & $\begin{array}{l}\text { Current } \\
\text { cigarette } \\
\text { smokers }\end{array}$ & $\begin{array}{l}\text { Other } \\
\text { smokers }\end{array}$ & Total \\
\hline $35-44$ & 0 & $1(12.5)$ & $7(87.5)$ & 0 & 8 \\
\hline $45-54$ & 0 & $2(14.3)$ & $10(71.4)$ & $2(14.3)$ & 14 \\
\hline $55-64$ & $2(5.7)$ & $10(28.6)$ & $20(57.1)$ & $3(8.6)$ & 35 \\
\hline $65-74$ & $3(7.9)$ & $18(47.4)$ & $13(34.2)$ & $4(10.5)$ & 38 \\
\hline $35-74$ & $5(5.3)$ & $31(32.6)$ & $50(52.6)$ & $9(9.5)$ & 95 \\
\hline \multicolumn{6}{|c|}{ Others } \\
\hline $35-44$ & $19(11.7)$ & $30(18.4)$ & $111(68.1)$ & $3(1.8)$ & 163 \\
\hline $45-54$ & $13(7.3)$ & $29(16.3)$ & $126(70.8)$ & $10(5.6)$ & 178 \\
\hline $55-64$ & $15(11.2)$ & $30(22.4)$ & $84(62.7)$ & $5(3.7)$ & 134 \\
\hline $65-74$ & $12(9.1)$ & $47(35.6)$ & $59(44.7)$ & $14(10.6)$ & 132 \\
\hline $35-74$ & $59(9.7)$ & $136(22.4)$ & $380(62.6)$ & $32(5.3)$ & 607 \\
\hline
\end{tabular}

Comparison of men with coronary disease and others:

Men aged 35-74:

1. Non-smokers: $0.30>p>0.20$

2. Ex-smokers: $0.05>p>0.02$

3. Current cigarette smokers: $0.1>p>0.05$.

\section{International comparison}

Tables 8 and 9 compare the frequency of cardiac pain and E.C.G. changes in men aged 35-64 in Staveley, Derbyshire, United Kingdom, with men aged 35-64 in three towns in Marion County, West Virginia, United States. The age-adjusted percentages in each case have been based on the combined populations (in both places). The E.C.G.s were classified by the same person in the two studies. 

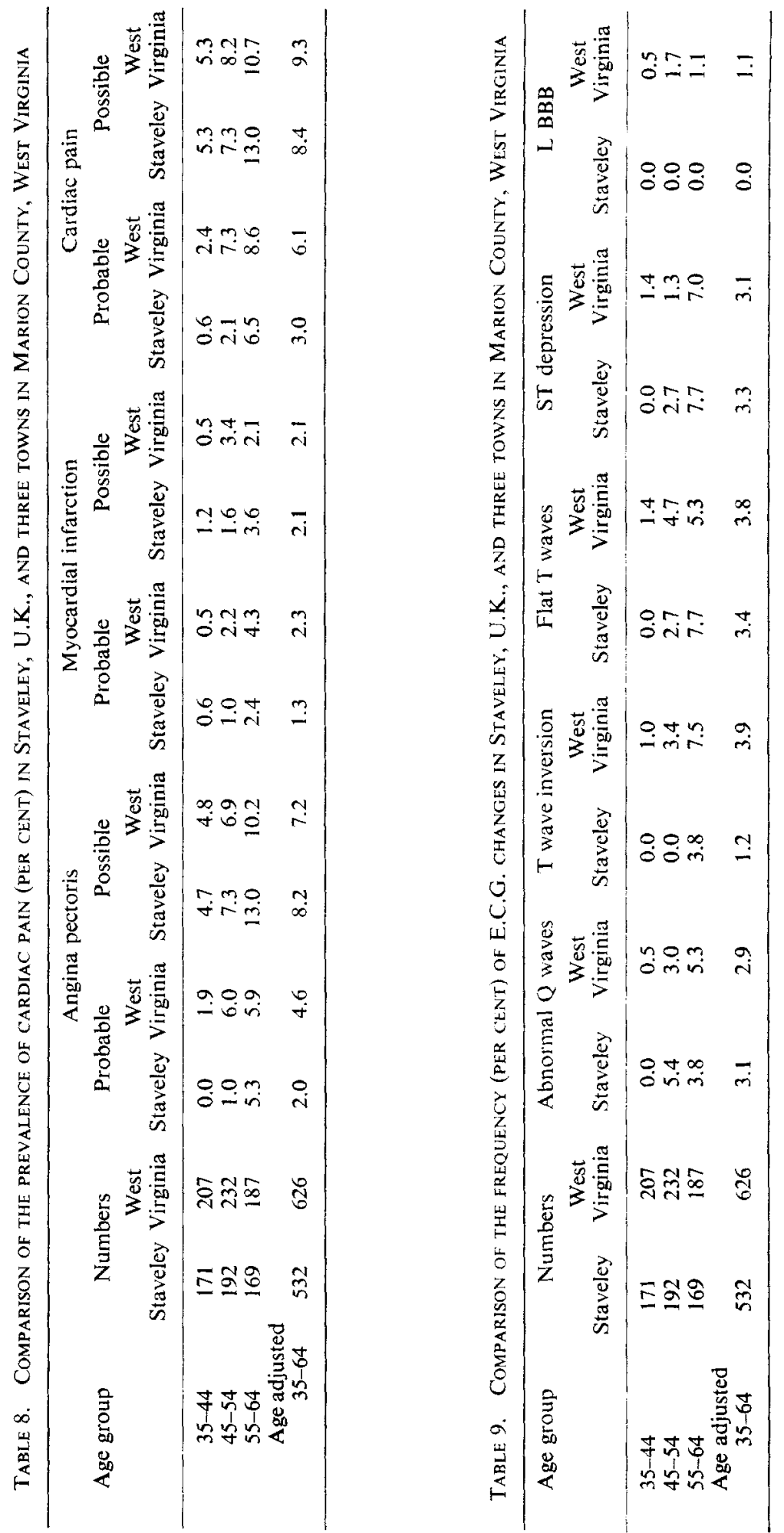
Probable cardiac pain was found about twice as often in West Virginia as in Staveley. The higher prevalence in the United States was attributable both to angina pectoris and to myocardial infarction pain. Possible cardiac pain and both its components appeared to be about equally frequent in each survey. Of the E.C.G. changes, T wave inversion and complete left bundle-branch block appeared to be commoner in West Virginia than in Staveley. But the other E.C.G. changes occurred equally frequently in each survey.

Table 10 compares the personal characteristics of the men in the two places. On the average, men in West Virginia were $4.8 \mathrm{~cm}(1.9 \mathrm{in}$.$) taller and 5.0 \mathrm{~kg}(11.0 \mathrm{lb})$ heavier than men of similar age in Staveley. The blood pressure was about $5 \mathrm{~mm} \mathrm{Hg} \mathrm{lower,}$ both systolic and diastolic, in West Virginia. It is likely that this difference was due to the circumstances under which the blood pressure was measured in the two places. In Staveley there was more coming and going which could possibly have elevated the blood pressure. There was a higher proportion of nonsmokers and an appreciably higher proportion of other smokers in West Virginia. Current cigarette smokers were more frequent in Staveley, particularly lighter smokers. Ex-smokers were roughly equally represented in both areas.

Table 10. Comparison of personal Characteristics of MEN aGed 35-64 in Staveley, U.K., AND THREE TOWNS IN MARION COUNTY, WEST VIRGINIA, U.S. (aGE aDJUSTEd to total POPULATION)

\begin{tabular}{lcc} 
& $\begin{array}{c}\text { Staveley } \\
\text { U.K. } \\
(532)\end{array}$ & $\begin{array}{c}\text { West Virginia } \\
\text { U.S. } \\
(626)\end{array}$ \\
\hline Physical characteristics & & \\
Standing height (cm) & 168.9 & 173.7 \\
Sitting height (cm) & 88.9 & 91.2 \\
Weight (kg) & 72.9 & 77.9 \\
Systolic BP & 145.5 & 140.7 \\
Diastolic BP (disappearance) & 90.3 & 85.2 \\
Smoking habits* & & \\
Non-smokers & 9.2 & 14.7 \\
Ex-smokers & 19.1 & 17.9 \\
Present smokers & & \\
1-14 cigarettes/day & 26.4 & 8.9 \\
15 cigarettes/day and over & 10.9 & 16.6 \\
All amounts & 67.4 & 55.5 \\
Other smokers & 4.3 & 11.6 \\
\hline
\end{tabular}

*In 0.3 per cent smoking habits were not recorded

\section{DISCUSSION}

\section{Occupational comparison}

The lower frequency of myocardial infarction-type pain and probable angina among the miners observed in this survey is in the direction which one might expect from the lower national mortality rates among miners. A previous survey in the Rhondda fach [9] had shown somewhat lower mortality rates from coronary disease among miners and exminers under 55 than other men. But the lack of any supporting E.C.G. differences between the occupational groups suggests that occupation cannot have played a very significant role in determining the prevalence of coronary heart 
disease in Staveley. This is in line with the conclusion reached in comparing miners and others in West Virginia. There we found inconsistent differences: probable myocardial infarction and possible angina were higher in nonminers than in miners while probable angina and possible myocardial infarction were higher in miners. But none of the differences reached the 5 per cent level of significance.

\section{Differences between those with and without coronary disease}

The survey was not designed primarily to study coronary disease. The related factors, therefore, were few. The consistent differences in blood pressure between the two groups is similar to that found in earlier surveys. Both the weight differences and the small smoking differences are in agreement with other studies $[10,11]$. Our earlier studies had led us to believe that ventilatory lung function was usually lower in those diagnosed as having coronary disease than in others. But while there was a small difference in this direction in the two older age groups, the difference was in the opposite direction in the younger men.

\section{International comparison}

The differences between the two surveys in the prevalence of cardiac pain and the E.C.G. changes are in the direction one would expect from the mortality statistics. It is, however, a little surprising that in addition to the higher frequency in the U.S. population of $T$ wave inversion, there was not also an excess of $Q$ wave abnormalities as noted by Reid and his colleagues [1]. A possible explanation could be that the combination of small numbers and mortality associated with $Q$ wave changes has resulted in such cases being eliminated from the population in West Virginia.

Our survey confirms the considerable differences in height and weight between middle-aged Americans and their British counterparts. The average heights in our surveys, however, were approximately $3 \mathrm{~cm}$ less in both countries than those recorded by Reid and his colleagues [1]. The average weight of the men in Staveley was similar to that reported by Reid and his colleagues for United Kingdom males. But the men in West Virginia were approximately $4 \mathrm{~kg}$ lighter than the United States males in Reid's surveys. The difference in weight does not explain the differences in the frequency of cardiac pain or E.C.G. abnormalities in the two countries.

\section{SUMMARY}

A survey of coronary disease has been carried out in a sample of men aged 35-74 living in Staveley, United Kingdom. The prevalence of cardiac pain based on standard questions and the frequency of certain electrocardiographic abnormalities was compared in miners and exminers, foundry and exfoundry workers, mixed dust and other exposure groups, and men who had never worked in dust or fumes. The findings have been compared with a similar survey conducted in three communities in Marion County, West Virginia, United States.

No striking occupational differences were found, though the prevalence of probable cardiac pain was slightly less in miners and exminers than in the other occupational groups. The prevalence of cardiac pain was twice as high in the United States as in the United Kingdom population. T wave inversion and left complete bundle-branch block occurred more frequently in the U.S. group. But abnormal Q waves, flat $T$ 
waves, ST depression and other E.C.G. changes were equally common in each country. The American men were nearly $5 \mathrm{~cm}$ taller and $5 \mathrm{~kg}$ heavier than the British men.

Of the etiological factors examined, weight and smoking were associated to a small amount with coronary disease. But the most striking association was with blood pressure. Systolic blood pressure was roughly $20 \mathrm{~mm} \mathrm{Hg}$ higher and diastolic blood pressure $10 \mathrm{~mm} \mathrm{Hg}$ higher in the coronary compared with the other group.

\section{REFERENCES}

1. Reid DD, Holland WW, Rose GA: An Anglo-American cardiovascular comparison. Lancet ii: $1375-1378,1967$

2. Higgins ITT, Gilson JC, Ferris BG, Jr, Waters WE, Campbell H, Higgins MW: Chronic respiratory disease in an industrial town: A nine-year follow-up study. Preliminary report. AJPH 58: 1667-1676, 1968

3. Higgins ITT, Higgins MW, Lockshin MD, Canale $\mathrm{N}$ : Coronary disease in mining communities in Marion County, West Virginia. J Chron Dis 22:165-176, 1969

4. Rose GA: The diagnosis of ischaemic heart pain and intermittent claudication in field surveys. Bull WHO 27: 645-658, 1962

5. Standardized Questionnaires on Respiratory Symptoms. A statement prepared for and approved by the Medical Research Council's Committee on the Aetiology of Chronic Bronchitis. Brit Med J 2:1665, 1960

6. Blackburn H, Keys A, Simonson E, Rautaharju P, Punsar S: The electrocardiogram in population studies. A classification study. Circulation 21:1160-1175, 1960

7. Medical Research Council's Committee on the Aetiology of Chronic Bronchitis. Definition and Classification of Chronic Bronchitis for Clinical and Epidemiological Purposes. Lancet 1: $775-779,1965$

8. McKerrow CB, McDermott M, Gilson JC: A spirometer for measuring the forced expiratory volume with a simple calibrating device. Lancet 1: 149-151, 1961

9. Higgins ITT, Cochrane AL, Thomas AJ: Epidemiological studies of coronary disease. Brit $\mathbf{J}$ Prev Soc Med 17: 153-165, 1963

10. Epstein FH, Ostrander LD, Johnson BG, Payne MW, Hayner NS, Keller JB, Francis T, Jr.: Epidemiological studies of cardiovascular disease in a total community-Tecumseh, Michigan. Ann Int Med 62: 1170-1187, 1965

11. Kannel WB, Dawber TR, Kagan A, Revotskie N, Stokes J, III: Factors in the development of coronary heart disease-Six year follow-up experience. Ann Int Med 55: 33-50, 1961 